Personalidade Acadêmica Homenageada:

Augustus B. Cochran III (Agnes Scott College)

\title{
LAS OCHENTAS: O PREÇO DO REFÚGIO
}

\section{LAS OCHENTAS: THE REFUGE PRICE}

\begin{abstract}
ANA FLÁVIA ANANIAS ALMEIDA
Graduanda em Direito, modalidade integral, pela Escola Superior Dom Helder Câmara. Belo Horizonte-MG. E-mail:anaflaviaollg@gmail.com.
\end{abstract}

\section{LAURA FERREIRA SILVA}

Graduanda em Direito, modalidade integral, pela Escola Superior Dom Helder Câmara. Belo Horizonte-MG. E-mail: laurafs209@hotmail.com.

\section{CAIO AUGUSTO SOUZA LARA}

Mestre e Doutor em Direito pela Faculdade de Direito da Universidade Federal de Minas Gerais - UFMG. Professor da Escola Superior Dom Helder Câmara. Pesquisador Associado ao Programa RECAJ-UFMG - Acesso à Justiça e Solução de Conflitos. Secretário de Comunicação do Conselho Nacional de Pesquisa e Pósgraduação em Direito - CONPEDI. Belo Horizonte-MG. E-mail: caiolarabh@yahoo.com.br.

\section{RESUMO}

O tema-problema da pesquisa que se pretende desenvolver é a vulnerabilidade econômica das refugiadas venezuelanas no Brasil e a prostituição como uma de suas consequências. A maior parte das refugiadas venezuelanas que se encontram em Boa Vista, Roraima, enfrentam graves situações de dificuldade no que diz respeito à inserção no mercado de trabalho, em decorrência da irregularidade. Por esse motivo, elas encontram um mercado que não proporciona 


\section{Personalidade Acadêmica Homenageada:}

Augustus B. Cochran III (Agnes Scott College)

carteira de trabalho, nem garantia de retorno e que coloca suas vidas em perigo, a prostituição. É preciso trazer à tona a problemática que gira em torno da vida dessas mulheres. O preço do refúgio vai muito além dos oitenta reais pagos por programa para que elas consigam se manter e manter suas famílias. Esse preço está associado a uma banalização, uma desproteção, um cárcere moral e uma vida que se transformou, de forma expressiva, não apenas devido à crise que alastra a Venezuela, mas por um abandono social. As mulheres que se encontram imersas no mercado de prostituição, por consequência de sua vulnerabilidade econômica, assumem uma capa de invisibilidade e marginalização social, utilizando de forma modificada a expressão de Hannah Arendt (2011) elas se tornam o refugo da terra. O problema objeto da investigação científica proposta é: quais os tipos de violação dos Direitos Humanos que as venezuelanas estão expostas ao buscar o refúgio no Brasil? A partir das reflexões preliminares sobre o tema, supõe-se que a violação dos Direitos Humanos contra as refugiadas venezuelanas residentes no Brasil está ligada com a situação de vulnerabilidade, principalmente econômica, uma vez que enfrentam uma divisão sexista do trabalho e a própria escassez dele. Nesse sentido, são submetidas a situações de extrema fragilidade, em busca da sobrevivência, se sujeitando a trabalhos não regulamentados, que põem em risco direitos como o direito à vida, igualdade e liberdade, além da segurança pessoal. O objetivo geral do trabalho é analisar a realidade vivenciada pelas refugiadas venezuelanas residentes no território brasileiro, trazendo, através de dados, a questão da vulnerabilidade econômica e a sua ligação com a prostituição, no estado de Roraima. A pesquisa que se propõe pertence à vertente metodológica jurídico-sociológica. No tocante ao tipo de investigação, foi escolhido, na classificação de Witker (1985) e Gustin (2010), o tipo jurídico-projetivo. O raciocínio desenvolvido na pesquisa será predominantemente dialético. De acordo com a técnica de análise de conteúdo, afirma-se que trata-se de uma pesquisa teórica, o que será possível a partir da análise de conteúdo dos textos doutrinários, normas e demais dados colhidos na pesquisa. Como marco teórico foi utilizada a assertiva de Simone de Beauvoir (1967), presente em sua obra "O segundo sexo". Como conclusão parcial desse projeto de iniciação científica têm-se que as venezuelanas entram no mercado da 


\section{Personalidade Acadêmica Homenageada:}

\section{Augustus B. Cochran III (Agnes Scott College)}

prostituição não de forma espontânea, mas há uma questão de necessidade, um verdadeiro estado de vulnerabilidade que faz com que essas mulheres se sujeitem a tal ato. A falta de efetividade nas leis que envolvem a questão trabalhista no âmbito dos imigrantes faz com que, cada vez mais, essa modalidade de profissão seja a resposta aos problemas dessas mulheres. Há no Brasil um despreparo para/com essas mulheres, que, por consequência, tem diretamente seus Direitos Humanos violados, mesmo com a violência a tendência é de que o número das "Las Ochentas" aumente, uma vez que há uma grande entrada dessas mulheres e uma crise cada vez mais profunda de desemprego, acarretado com a xenofobia e o machismo.

PALAVRA-CHAVE: Direitos Humanos; Vulnerabilidade Econômica; Prostituição; Exploração.

\section{REFERÊNCIAS}

ARENDT, Hannah. As origens do totalitarismo. São Paulo: Companhia das Letras, 2011, pp. 399-422.

BEAUVOIR, Simone de. 0 segundo sexo. 2. ed. São Paulo: Difusão Europeia do Livro, 1967.

BRASIL. Secretaria Nacional de Justiça. Refúgio em números. Disponível em: https://www.justica.gov.br/news/de-10-1-mil-refugiados-apenas-5-1-mil-continuamno-brasil/refugio-em-numeros_1104.pdf/view. Acesso em: 4 abr. 2019.

DANIELLE ANONNI (Curitiba) (Comp.). Direito Internacional dos refugiados e o Brasil. 2018. Disponível em: http://gedai.com.br/wpcontent/uploads/2018/08/ivro_\%20Direito\%20Internacional\%20dos\%20Refugiados $\% 20$ e $200 \% 20$ Brasil.compressed-ilovepdf-compressed.pdf. Acesso em: 7 abr. 2019.

FRAZÃO, Dilva. Simone de Beauvoir: Escritora e filósofa francesa. 2019. Disponível em: https://www.ebiografia.com/simone_de_beauvoir/. Acesso em: 8 maio 2019. 
Personalidade Acadêmica Homenageada:

Augustus B. Cochran III (Agnes Scott College)

DIREITOS HUMANOS: Desafios e perspectivas contemporâneas. Brasilia: Tribunal Superior do Trabalho, v. 75, n. 1, 2009. Disponível em: https://siabi.trt4.jus.br/biblioteca/acervo/Doutrina/artigos/Revista\%20do\%20Tribunal \%20Superior\%20do\%20Trabalho/2009/n\%201/Revista\%20do\%20Tribunal\%20Super ior\%20do\%20Trabalho,\%20v\%2075,\%20n\%201,\%20p\%20107-113,\%20janmar\%202009.pdf. Acesso em: 30 abr. 2019.

SIMÕES, Gustavo da Frota (Curitiba) (Org.). Perfil sociodemográfico e laboral da imigração venezuelana no Brasil. 2017. Disponível em: https://portaldeimigracao.mj.gov.br/images/publicacoes/Perfil_Sociodemografico_e_I aboral_venezuelanos_Brasil.pdf. Acesso em: 8 maio 2019.

GUSTIN, Miracy Barbosa de Sousa; DIAS, Maria Tereza Fonseca. (Re)pensando a pesquisa jurídica: teoria e prática. 3ª . ed. Belo Horizonte: Del Rey, 2010.

HUMAN RIGHTS WATCH. O êxodo venezuelano: a necessidade de uma resposta regional a uma crise migratória sem precedentes. 2018. Disponível em: https://www.hrw.org/sites/default/files/report_pdf/venezuela0918port.pdf. Acesso em: 8 maio 2019.

MISAILIDIS, Mirta G. Lerena; MOURA, Stéphanie Winck Ribeiro de. A política imigratória seletiva e a tutela jurídica dos trabalhadores imigrantes no Brasil. Revista Jurídica - UNICURITIBA. Curitiba: Unicuritiba, v. 2, n. 39, 2015. Disponível em: http://revista.unicuritiba.edu.br/index.php/RevJur/article/view/1544/1058. Acesso em: 20 maio 2019.

POLICY PAPER (Rio de Janeiro). Desafio migratório em Roraima: Repensando a política e gestão da migração no Brasil. 2018. FGV DAPP. Disponível em: http://dapp.fgv.br/wp-content/uploads/2018/03/Desafio-migrato\%CC\%81 rio-Roraimapolicy-paper.pdf. Acesso em: 8 maio 2019.

TEXTOS E DEBATES. Relações bilaterais entre Brasil e Venezuela através dos estados de Roraima e Bolívar. Roraima: Ufrr, 2012. Disponível em: https://revista.ufrr.br/textosedebates/article/view/1591. Acesso em: 8 maio 2019.

ROSANA BAENINGER (São Paulo) (Comp.). Migrações venezuelanas. 2018. Unicamp. Disponível em: https://www.nepo.unicamp.br/publicacoes/livros/mig_venezuelanas/migracoes_vene zuelanas.pdf. Acesso em: 7 abr. 2019.

SCHWINN, Simone Andrea; PORTELA, Êmily de Amarante. O Brasil e a imigração venezuelana: a (des)organização da política migratória brasileira. 2018. Disponível em: https://7seminario.furg.br/images/arquivo/203.pdf. Acesso em: 8 maio 2019.

WITKER, Jorge. Como elaborar uma tesis en derecho: pautas metodológicas y técnicas para el estudiante o investigador del derecho. Madrid: Civitas, 1985. 